\title{
A rare case of abdominal lymphangioma masquerading an adenaxal mass
}

\author{
Mukta Agarwal ${ }^{1}$, Divendu Bhushan ${ }^{2}$, Prashant Singh $^{3}$, Poonam Bhadani ${ }^{4}$ \\ ${ }^{1}$ Department of Obstetrics and Gynaecology, AIIMS, Patna, India \\ ${ }^{2}$ Department of Medicine, PARAS- HMRI Hospital, Patna \\ ${ }^{3}$ Department of General Surgery, AIIMS, Patna, India \\ ${ }^{4}$ Department of Pathology, AIIMS, Patna, India
}

Received: 14 March 2016

Revised: 13 April 2016

Accepted: 14 April 2016

\section{*Correspondence:}

Dr. Mukta Agarwal,

E-mail: agarwal_mukta2006@yahoo.co.in

Copyright: () the author(s), publisher and licensee Medip Academy. This is an open-access article distributed under the terms of the Creative Commons Attribution Non-Commercial License, which permits unrestricted non-commercial use, distribution, and reproduction in any medium, provided the original work is properly cited.

\begin{abstract}
Lymphangioma is an uncommon benign tumour of the lymphatic system. It can be localized (spleen, liver or thorax) or generalized. An abdominal location is exceptional (5\%) and majority of cases occur in early childhood and it rarely presents in adulthood. Retroperitoneal lymphangioma account for less than $1 \%$ of all lymphangiomas here we present a rare case of retroperitoneal lymphangioma and patient presented as adenaxal mass.
\end{abstract}

Keywords: Lymphangioma, Retroperitoneal, adenaxal mass

\section{INTRODUCTION}

Adnexal masses, whether benign or malignant are commonly encountered in gynaecology practice, but sometimes few rare entities are found when we operate for some adenaxal mass. Retroperitoneal lymphangioma is one of those rare entities, which we have encountered recently during laparotomy for a benign adenaxal mass.

Retroperitoneal lymphangioma is a rare benign tumour of retropeitoneum which develop from retroperitoneal lymphatics and account less than one percent of all cystic lymphangiomas. Most of the cystic lymphangiomas are usually present in infancy only and very few cases are reported in adulthood. A lymphangioma is a benign proliferation of lymphatic tissue believed to originate from the early sequestration of lymphatic vessels that fail to establish connections with normal draining lymphatic's at about 14-20 weeks of intrauterine life. ${ }^{1}$ Lymphangiomas are therefore considered a congenital rather than an acquired tumour. After birth, they can become markedly dilated as a result of both the collection of fluid and the budding of pre-existing spaces. ${ }^{2}$ The other explanations for the origin of lymphangioma include obstruction of lymph channels secondary to fibrosis, inflammation, trauma, node degeneration; or failure of endothelial secretory function, which explains the pathophysiology of this in adults. Not only these are such rare entity, but they also pose diagnostic challenges to clinician, that is the reason we found this case worthy of reporting to the medical fraternity.

\section{CASE REPORT}

Mrs. A, a 55 years old female was first seen in medicine OPD with complaints of pain in right lower abdomen and patient was referred to the department of Gynaecology. In history, Patient told that she is having continuous dull aching pain in right lower abdomen and occasional nausea and vomiting for past one and half months. Patient was having no other bowel complaints. Patient was postmenopausal for last 15 years with normal previous 
menstrual cycles and no history of post-menopausal bleeding. Patient was $\mathrm{P}_{2} \mathrm{~L}_{2}$ with both normal deliveries, last delivery was about 30 years back and bilateral tubal ligation was done after that. Past medical history revealed nothing significant except history of filariasis in childhood. On examination, Vitals were stable, pallor and icterus were absent and there was no significant lymphadenopathy. On per-abdomen examination, a 20 weeks gravid uterus size abdomino-pelvic mass was felt, which was side to side mobile and was non-tender. Perspeculum examination was normal and on per-vaginum examination, a large, firm, non-tender mass of 20 weeks gravid uterus size was felt, which is continuous with uterus and extending into right fornix, left fornix was free, hence provisional diagnosis of either subserous fibroid or right adenaxal mass was made and patient was subjected to ultrasonographic examination, which revealed a large 10X7 cms well defined heterogeneous hypoechoiec soft tissue lesion in right adenaxa with another ill-defined multiseptated cystic lesion with small soft tissue component seen between uterus and the large soft tissue lesion as mentioned above. There was no communication between the two lesions. CT- scan was advised but patient refused due to cost constraint. CA125 was 9.9U/ml, Pap smear was negative for intraepithelial malignant lesion and other blood bio-chemical parameters were within normal limits. After proper work up, patient was taken up for exploratory laparotomy and proceed. Abdomen was opened with mid line vertical incision, on opening abdomen, uterus was of normal size with normal bilateral tubes and ovaries. A large 15 X 10 cms pedunculated fibroid with superficial vessels was noted attached to round ligament of right side. Multiple cystic masses (? Lymphangioma) were palpated retroperitoneally along right ovarian vessels. Right infundibulo-pelvic ligament was also visualized after dissection of folds of lymphangioma sac. Hysterectomy was done and a surgeon was called for opinion and he also made the provisional diagnosis of retroperitoneal lymphangioma. Then peritoneum was mobilized up to hepatic flexure and large bowel was mobilized medially. All cystic masses containing straw coloured fluid were excised with ligating the lower side up to lower pole of right kidney along with the ovarian vessels. The specimen was sent for histopathological examination. Retroperitoneal drain was placed and peritoneum reposited. Abdomen was closed. Post-operative period remained uneventful and drain was removed on $5^{\text {th }}$ postoperative day. Later on, histopathological report confirmed the diagnosis of broad ligament fibroid with lymphangioma.

\section{DISCUSSION}

Lymphangioma is an uncommon benign tumour of the lymphatic system and they can evolve as either hamartomas or lymphangiectasis. ${ }^{3}$ These can be classified into four categories- capillary lymphangioma, cavernous lymphangioma, cystic lymphangioma (hygroma) and heamolymphangioma.it can be localized (spleen, liver or thorax) or generalized. The most common site is head and neck region followed by axilla. An abdominal location is exceptional $(5 \%)$ and majority of cases occur in early childhood and it rarely presents in adulthood. Abdominal lesion can arise from mesentery, greater omentum or retroperitoneum. Developmentally, they arise from sequestration of lymphatic tissue that fail to communicate normally with the lymphatic system. ${ }^{4}$ These abnormal channels dilate to form uni or multi-loculated cysts, which are filled with chylous or serous material and lined with endothelium.

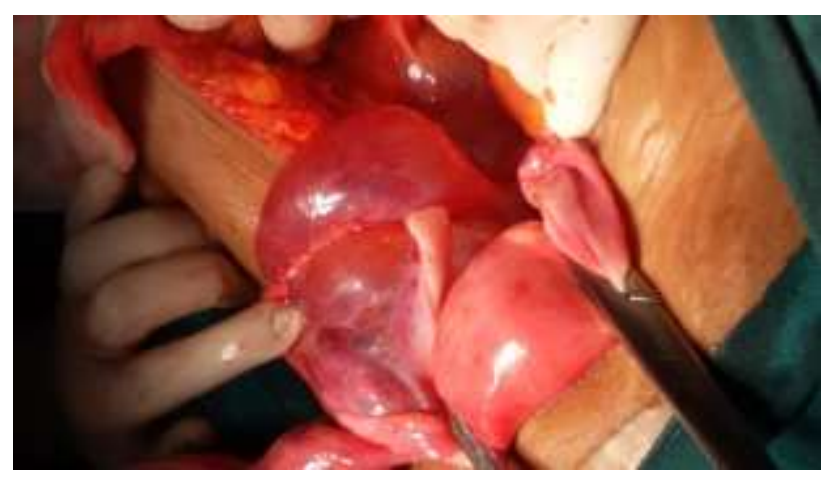

Figure 1: Dissected lymphangioma sac with uterus, bilateral and ovaries after opening the abdomen.

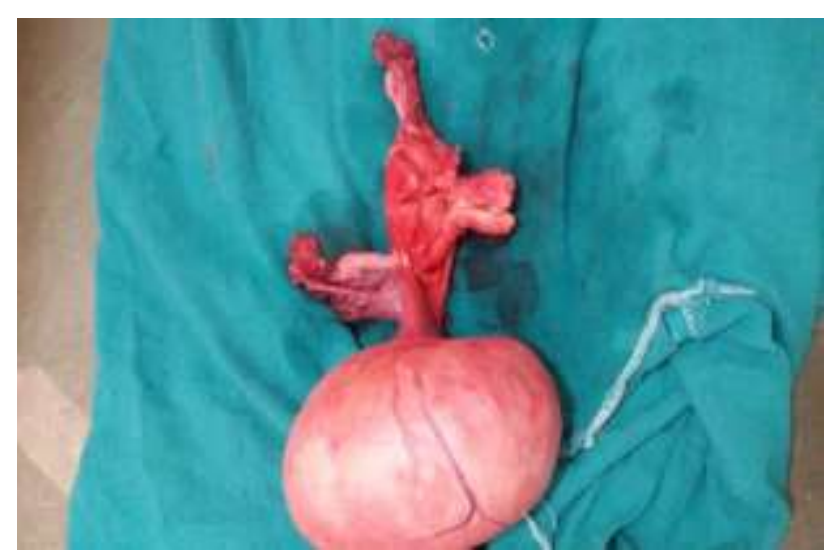

Figure 2: Gross specimen showing uterus, bilateral tubes, ovaries and round ligament fibroid.

Retroperitoneal lymphangioma accounts for less than $1 \%$ of all lymphangiomas on, which searching PubMed for retroperitoneal lymphangioma, they are almost always benign and can be of cavernous and cystic variety. ${ }^{5}$ Retroperitoneal lymphangioma can remain asymptomatic and detected incidentally during radiological procedures, surgery or autopsy, or can present with vague abdominal pain, nausea (as in our case) or slow growing abdominal mass. Infrequent complications are ascites, bleeding or rupture. ${ }^{6}$

Pre-operative diagnosis is usually difficult and lesion is encountered during laparotomy or laparoscopy. However, 
ultrasound, CT and MRI can help in making the diagnosis. Final diagnosis is usually made by pathological examination, which include wellcircumscribed cystic lesion with stroma containing meshwork of collagen and fibrous tissue with or without endothelial lining and aggregates of lymphoid tissue in the wall. ${ }^{7}$

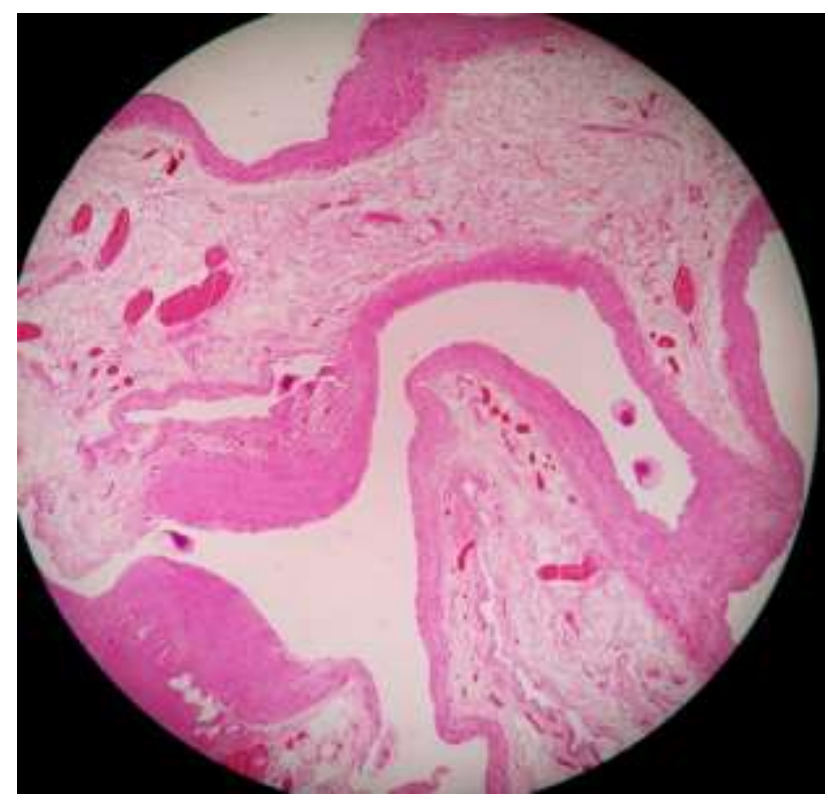

Figure 3: Histopathological picture of lymphangioma.

Preferred treatment is surgical excision to avoid further growth, infection, rupture of bleeding. Outcome following complete resection is good.

In literature, a total 366 case reports of abdominal lymphangioma can be seen, out of which, less than 200 belong to adult cases. ${ }^{8-15}$

\section{CONCLUSION}

Retroperitoneal lymphangiomas are rare tumour of adults. Apart from being a rare entity, it also poses diagnostic dilemma and final diagnosis is often made after surgical exploration only. Therefore, we found it worth to report a case of retroperitoneal lymphangioma in adult female. Of various possibilities of adnexal masses in adult females, retroperitoneal lymphangioma though rare is one of the possibility.

Funding: No funding sources Conflict of interest: None declared Ethical approval: Not required

\section{REFERENCES}

1. Salder TW. Langeman's Medical Embryology. $7^{\text {th }}$. Williams \& Wilkins; 1995.

2. Wilson SR, Bohrer S, Losanda R, Price AP. Retroperitoneal lymphangioma: an unusual location and presentation. J Pediatr Surg. 2006;41(3):603-5.

3. Cutillo DP, Swayne LC, Cucco J, Dougan H. CT and MR imaging in cystic abdominal lymphangiomatosis. J Comput Assist Tomogr. 1989;13:534-6.

4. de Perrot M, Rostan O, Morel P, Le Coultre C. Abdominal lymphangioma in adults and children. $\mathrm{Br}$ J Surg. 1998;85:395-7.

5. Fonkalsrud EW. Congenital malformations of the lymphatic system. Semin Pediatr Surg. 1994;3:62-9.

6. Yang DM, Jung DH, Kim H, Kang JH, Kim SH, Kim JH. Retroperitoneal cystic masses: CT, clinical, and pathologic findings and literature review. Radiographics. 2004;24:1353-65.

7. Hauser $\mathrm{H}$, Mischinger HJ, Beham A, Berger A, Cerwenka H, Razmara J. Cystic retroperitoneal lymphangiomas in adults. Eur J Surg Oncol. 1997;23:322-6.

8. Roisman I, Manny J, Fields S, Shiloni E. Intraabdominal lymphangioma. Br j Surg. 1989;76:485-9.

9. Thomas AM, Leung A, Lynn J. Abdominal cystic lymphangiomatosis: report of a case and review of the literature. Br J Radiol. 1985;58:467-9.

10. Chan IYF, Khoo J. Retroperitoneal lymphangioma in an adult. J HK Coll Radiol. 2003;6:94-6.

11. Bonhomme A, Broeders A, Oyen RH, Stas M, De Wever I, Baert AL. Cystic lymphangioma of the retroperitoneum. Clin Radiol. 2001;56:156-8.

12. Bhavsar T, Saeed-Vafa D, Harbison S, Inniss S. Retroperitoneal cystic lymphangioma an an adult: a case report and review of the literature. The World Journal of Gastrointestinal Pathophysiology. 2010;1(5):171-6.

13. Cherk M, Nikfarjam M, Christophi C. Retroperitoneal lymphangioma. Asian J Surg. 2006;29:51-4.

14. Koshy A, Tandon RK, Kapur BM, Rao KV, Joshi K. Retroperitoneal lymphangioma. A case report with review of the literature. Am J Gastroenterol. 1978;69:485- 90.

15. Tripathy M, Prasad S, Karwasra R. Retroperitoneal lymphangioma in an adult: A case report of a rare clinical entity.Case Rep Surg. 2015;732531. PMC 4381689. Doi: 10.1155/2015/732531.

Cite this article as: Agarwal $\mathrm{M}$, Bhushan D, Singh P, Bhadani P. A rare case of abdominal lymphangioma masquerading an adenaxal mass. Int J Reprod Contracept Obstet Gynecol 2016;5:1637-9. 